is by far the largest of those treated in this part, having 255 species. In this family the largest genera are Lithophragma with 20 species; Heuchera, 72; Therefon, 10; Saxifraga, 7; Muscaria, 7; Micranthes, 56; Spatularia, 7, and Leptasea, 15 . The next family in number of species is Hydrangeaceae with 52, and here the genus Philadelphus is the dominant one, with 36 species. Of the remaining families only Cunoniaceae and Hamamelidaceae have more than one species, the former having two and the latter four. The total number of species described in this part is 317 , among which one finds a considerable number of new species.

The University of Nebraska.

Charles E. Bessey.

\section{WORK AT THE LAKE LABORATORY FOR THE SEASON OF 1905.}

THE work in the past summer at the Lake Laboratory was, perhaps, the most successful of any session that has been spent there and distinctly encouraging for successful sessions in the future. Of the twenty-six students enrolled, eleven were college or university graduates; two having the title of $\mathrm{Ph} . \mathrm{D}$. and five that of master. Fifteen of the number were engaged in advanced or research work of university or graduate grade and in most cases for university credit; four were engaged in advanced work under the direction of the instructors, while six were doing independent research work for part or all of the time. Seven of the number are teachers in a university or college and two teachers in high schools, eleven being now or recently engaged in teaching in some capacity.

The following institutions were represented there this season: Cincinnati University, Columbia University, Denison University, De Pauw University, German Wallace College, Johns Hopkins University, Kenyon College, Ohio University, Ohio Northern University, Ohio State University, Ohio Wesleyan University and Miami University. If we include institutions which have been represented within the last few years we should add to these, Chicago, Michigan, Nebraska, Stanford, Amherst, Cornell, Antioch and Fargo, which have been represented either by investigators or by students.

A very enjoyable and profitable feature of this season's session was the meeting of the American Microscopical Society which brought a number of prominent scientific workers from various parts of the country and especially from Ohio, the Ohio Academy of Science holding a field meeting at the same time. This meeting consisted of the presentation of a number of scientific papers which were read at the laboratory and to which all the students were invited; an evening lecture by the president and social meetings, the most prominent of which was the luncheon which the university gave to the visiting members.

As heretofore, much attention has been given to original investigation and some of the more important topics studied this year are: 'The Brain of Amia,' by Professor Charles Brookover, Buchtel College; 'The Naididæ of Cedar Point,' by Professor L. B. Walton; 'Studies on the Life History of the Catfish and Investigations of Protozoa,' by Professor F. L. Landacre; 'Studies of the Insects which act as Scavengers of the Beach Débris,' by W. B. Herms ; 'Correlation Studies of Toads,' by Professor W. E. Kellicott; 'On the Flora of Cedar Point,' by Otto E. Jennings, and on the 'Protozoa of Sandusky Bay,' by Miss L. C. Riddle. The results of some of these studies will appear in published papers in the near future; others will doubtless be continued for more complete results.

\section{Herbert Osborn.}

\section{T'HE BRITISH ASSOCIATION. ${ }^{1}$}

THE list of officers for the seventy-sixth meeting of the British Association, which will open at York on August 1, next, is now practically completed. The meeting promises to be one of great interest. It was at York that the association came into being in 1831, when Lord Milton (afterward Lord Fitzwilliam) was president, and the attendance numbered only 353 persons. Thirteen years later the association again met in York, with the Rev. G. Peacock as president, and yet a third time

\footnotetext{
${ }^{1}$ The London Times.
} 